\title{
PENGAPLIKASIAN SIMBIOSIS DAN ARSITEKTUR RESILIENSI DALAM DESAIN SENTRA BUDIDAYA DAN PENGOLAHAN BANDENG ADAPTIF DI TAMBAKREJO
}

\author{
Marcellin Gaby Sunyoto ${ }^{1)}$, Rudy Trisno ${ }^{2)}$ \\ 1) Program Studi S1 Arsitektur, Fakultas Teknik, Universitas Tarumanagara, \\ marcellin.315170100@stu.untar.ac.id \\ 2) Program Studi S1 Arsitektur, Fakultas Teknik, Universitas Tarumanagara, rudyt@ft.untar.ac.id
}

Masuk: 04-07-2021, revisi: 14-08-2021, diterima untuk diterbitkan: 23-10-2021

\begin{abstract}
Abstrak
Hubungan timbal balik antara manusia dan alam memiliki keterikatan yang tidak bisa dipisahkan satu dengan yang lainnya. Ketergantungan manusia terhadap pemanfaatan sumber daya alam secara berlebihan menyebabkan ketidakseimbangan ekosistem dan memunculkan permasalahan seperti salah satunya banjir rob di area pesisir. "Tanadah" merupakan sebuah proyek sentra budidaya dan pengolahan adaptif di Tambakrejo, Semarang Utara yang merupakan kawasan yang dikenal karna budidaya dan pengolahan Ikan Bandeng (ikon oleh-oleh Kota Semarang). Selain itu, letaknya yang berbatasan dengan Laut Jawa menyebabkan kawasan ini juga dikenal karna intensitas banjir rob yang sering terjadi. Tujuan kehadiran proyek ini adalah untuk meningkatkan kreativitas dan menstabilkan perekonomian masyarakat Tambakrejo tanpa harus mengkhawatirkan ancaman bencana banjir rob setiap bulannya. Sehingga, masyarakat diharapkan tetap dapat bekerja dengan efektif dan produktif baik dalam kondisi kering maupun kondisi banjir sekalipun, serta tetap mendapatkan tempat pengsungsian yang layak dalam kondisi banjir. Metode yang digunakan yaitu dengan penelitian kualitatif dan survey dengan memperhatikan beberapa prinsip perancangan seperti Simbiosis oleh Kisho Kurokawa, dan Arsitektur Resiliensi yang mengacu pada ekologi. Kesimpulan dari proyek penelitian ini adalah untuk mewadahi masyarakat Tambakrejo agar tidak terhambat oleh kehadiran banjir rob dalam berkegiatan dan beraktivitas baik dalam aspek ekonomi, budaya maupun sosial. Temuan yang dihasilkan yaitu menghasilkan bangunan yang adaptif sehingga tetap dapat digunakan saat kondisi kering (pasar) maupun banjir (shelter).
\end{abstract}

Kata kunci: adaptif; banjir rob; ekologi; arsitektur resiliensi; simbiosis

\begin{abstract}
The reciprocal relationship between humans and nature has an inseparable bond between one another. Human dependence on using natural resources causes ecosystem imbalances and raises problems such as tidal flooding in coastal areas. "Tanadah" is an adaptive cultivation and processing center project in Tambakrejo, North Semarang which is known for their Milkfish cultivation. Then, Its located near the Java Sea, so this area is also known for the intensity of tidal floods that often occur. The purpose of this project is to increase creativity and stabilize the economy of the Tambakrejo, so they don't have to worry about the threat of tidal flooding every month. Thus, the community is expected to continue to work effectively and productively in both dry and flood conditions, as well as can still get a proper place of refuge in flood conditions. The method used is qualitative research and surveys, with referencing to several design principles such as Symbiosis by Kisho Kurokawa, Resilience Architecture and Ecology. The conclusion of this project study is to accommodate the Tambakrejo community so that they are not disturbed by the presence of tidal flooding in their activities such in economic, cultural or social aspects. The novelty is an adaptive buildings designs that can still be used during dry (market) or flooded (shelter) conditions.
\end{abstract}

Keywords: adaptive; ecology; resilience architecture; symbiosis; tidal flood 


\section{PENDAHULUAN}

\section{Isu: Bencana Banjir Rob}

Menurut Badan Nasional Penanggulangan Bencana (2020), banjir merupakan bencana paling sering terjadi dan menjadi perhatian pemerintah dengan catatan kasus mencapai 1000 kasus per tahun. (Moerti, 2020)

Kota Semarang sendiri merupakan salah satu daerah di Pulau Jawa yang rawan terkena banjir akibat pasang-surut air laut. Berdasarkan data BPBD Kota Semarang (2020) Banjir rob menjadi banjir yang paling sering terjadi dengan rata-rata 50 kasus per tahunnya. Hingga muncul slogan yang dikenal oleh masyarakat luas yaitu "Semarang Kaline Banjir" yang dalam Bahasa Indonesia berarti "Semarang Sungainya Banjir". (Badan Penanggulangan Bencana Daerah Kota Semarang, 2020)

Berdasarkan (Dinas Komunikasi dan Informatika Kota Semarang, 2019), Wilayah Semarang Utara merupakan wilayah yang paling sering terkena banjir rob karna berbatasan langsung dengan Laut Jawa dan memiliki topografi yang relatif rendah yakni dengan kemiringan sekitar $0-2 \%$. Selain itu, abrasi di pesisir Semarang Utara tiap tahunnya semakin meningkat walaupun sudah dilakukan beberapa tindakan pencegahan seperti penanaman mangrove dan pemasangan batu pemecah ombak atau breakwater. Keadaan ini diperparah dengan penurunan permukaan Tanah di Semarang Utara yang mencapai $15-20 \mathrm{~cm}$ tiap tahunnya. (Nuswantoro, 2020)

\section{Latar Belakang}

Adanya banjir rob yang terjadi di Kelurahan Tambakrejo cukup menganggu dan menghambat penduduk dalam menjalankan aktivitas sehari-hari, seperti bersekolah, bekerja, berjualan, menangkap ikan di laut, dan juga mempersulit proses distribusi hasil tangkapan nelayan ke pasar. Sehingga secara tidak langsung, bencana banjir rob ini melemahkan roda perekonomian masyarakat pesisir yang berujung pada meningkatnya angka kemiskinan di wilayah Tambakrejo setiap tahunnya. (Wibowo, 2021)

Hal inilah yang melatarbelakangi perancangan proyek "Tanadah: Sentra Budidaya dan Pengolahan Ikan Bandeng Adaptif di Tambakrejo" dimana proyek ini akan menjadi Wadah Ekonomi bagi para penduduk agar dapat tetap menjalankan aktivitas, memenuhi kebutuhan sehari-hari, mengembangkan potensi nya sebagai salah satu pemasok utama Ikan Bandeng segar dan hasil olahan Bandeng khas Semarang dikala banjir rob terjadi di Tambakrejo. Serta, menjadi Wadah Budaya dan Keagamaan bagi masyarakat pesisir Tambakrejo yang menganut Islam Abangan sebagai tempat melakukan silahturahmi, upacara, pesta, dan kegiatan adat lainnya. Selain itu saat terjadi banjir, menjadi Wadah Penampungan (shelter) banjir rob untuk masyarakat pesisir yang akan melakukan evakuasi.

\section{Lokasi}

Kelurahan Tambakrejo memiliki luas area $74.25 \mathrm{Ha}$ dan menjadi salah satu kelurahan yang menjadi titik rawan banjir rob di Semarang Utara. Hal ini disebabkan oleh kondisi geografis Tambakrejo sendiri yang hanya memiliki tingkat kemiringan daratan 0-2\% dengan sebagian besar wilayahnya hampir sama tingginya dengan permukaan laut (rendah-landai) dengan ketinggian daratan dari permukaan laut hanya $\pm 5 \mathrm{~m}$.

\section{Rumusan Permasalahan}

Rumusan masalah yang timbul adalah apa yang dimaksud simbiosis dan bagaimana menerapkannya pada desain arsitektur? Apa itu arsitektur resiliensi dan bagaimana penerapannya pada desain arsitektur? Bagaimana mendesain sebuah sentra budidaya dan pengolahan bandeng agar dapat beradaptasi dengan kondisi alam sekitar yang sering mengalami banjir rob? 


\section{Tujuan}

Secara garis besar proyek ini bertujuan untuk menjawab permasalahan banjir rob di wilayah pesisir Semarang Utara dengan pengaplikasian prinsip simbiosis dan arsitektur resiliensi dalam desain Sentra Budidaya Dan Pengolahan Ikan Bandeng yang adaptif.

\section{Untuk Kawasan Tambakrejo}

Dengan terbangunnya proyek ini dapat dimanfaatkan oleh warga sebagai sumber mata pencaharian dalam bidang aquaculture atau lebih tepatnya budidaya dan pengolahan Ikan Bandeng, sebagai tempat komunal untuk melakukan upacara adat dan ritual keagamaan bagi masyarakat Tambakrejo, serta menjadi bangunan adaptif yang dapat menjadi shelter/penampungan dikala banjir rob (amphibious / floating building systems). Sehingga, masyarakat tak lagi harus takut dan bergantung pada banjir rob yang menyulitkan mereka.

\section{Untuk Kota Semarang}

Manfaat proyek ini untuk Kota Semarang yaitu dapat menjadi salah satu obyek destinasi wisata baru yang adaptif dan hidup di kala banjir rob, seperti festival kapal, perlombaan dan kompetisi, serta aktivitas lainnya yang dapat menghidupkan kawasan disaat bencana datang.

Selain itu, diharapkan proyek ini dapat meningkatkan kesadaran dan kepekaan pemerintah untuk tidak hanya menanggulangi banjir rob, melainkan dapat memanfaatkan banjir rob dengan strategi dan teknologi yang terbaru.

\section{Sustainable Development Goals}
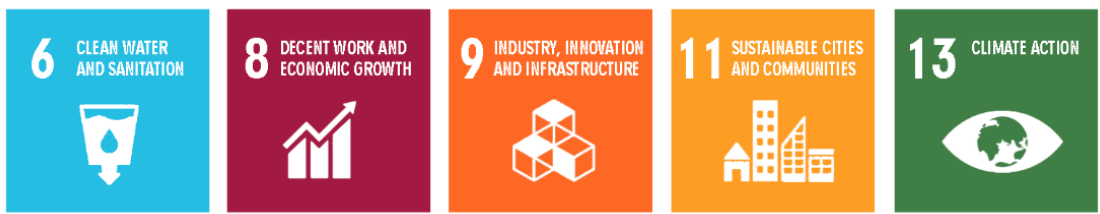

Gambar 1. Aspek Sustainable Development Goals yang Diinginkan

Sumber: http://sdgs.bappenas.go.id/, 2021

\section{KAJIAN LITERATUR}

\section{Ekologi}

Kata ekologi pertama kali diperkenalkan oleh Ernst Haeckel seorang ahli biologi Jerman pada tahun 1866. Menurut Ernst Haeckel ekologi adalah ilmu yang komprehensif yang mempelajari hubungan antar organisme dengan lingkungannya.

Berdasarkan perkembangannya ekologi disebut sebagai ilmu dasar lingkungan, ilmu yang mempelajari makhluk hidup dalam rumah tangganya atau ilmu yang mempelajari seluruh pola hubungan timbal balik antara makhluk hidup sesamanya dengan komponen di sekitarnya.

Ilmu ekologi menganut prinsip keseimbangan dan keharmonisan semua komponen alam. Terjadinya bencana alam merupakan contoh keseimbangan dan keharmonisan alam yang terganggu. (Wikipedia Indonesia, 2021)

\section{Bencana Banjir Rob di Pesisir Semarang}

Menurut Pusat Krisis Kementerian Kesehatan Republik Indonesia (2016) Banjir rob (akibatnya naiknya permukaan air laut) merupakan banjir yang disebabkan oleh pasangnya air laut yang mengakibatkan gelombang tinggi serta angin badai di sepanjang pantai dengan menggenangi daratan. (Erlani \& Nugrahandika, 2019)

Intensitas terjadinya peristiwa banjir rob dipengaruhi oleh kenaikan permukaan air laut yang berhubungan dengan gaya tarik atau gravitasi bumi terhadap bulan dan matahari. Siklus ini berlangsung secara rutin dan kontinu setiap bulannya. (Taufiqurrahman, 2017) 


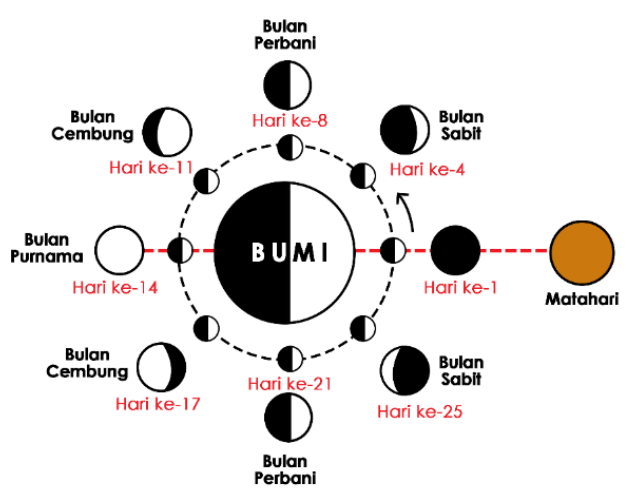

Gambar 2. Siklus Pergerakan Bulan terhadap Bumi Sumber: https://www.infoastronomy.org/, 2021

Berdasarkan (Taufiqurrahman, 2017), Kondisi air laut pasang terjadi 2 kali yaitu saat bulan purnama dan bulan baru. Secara garis besar, pasang surut permukaan air laut terjadi ketika: (Gambar 2)

a. Pasang Purnama / Spring Tide (Air Laut Pasang)

Terjadi ketika bulan, bumi, dan matahari berada pada garis sejajar sehingga mengakibatkan gaya gravitasi bulan purnama lebih kuat daripada bumi untuk menarik air laut. Terjadi 2 kali dalam sebulan yaitu minggu ke-1 dan ke-2 tiap bulannya.

b. Pasang Perbani / Neap Tide (Air Laut Surut)

Terjadi ketika bulan dan matahari membentuk garis tegak lurus terhadap bumi sehingga kekuatan matahari berlawanan dengan kekuatan bulan dan menyebabkan pasang perbani / surutnya air laut. Terjadi 2 kali dalam sebulan yaitu minggu ke-3 dan ke-4 tiap bulannya.

Dalam artikel (Erlani \& Nugrahandika, 2019), Macam-macam kategori kedalaman banjir rob: Kedalaman Rendah

a. Ketinggian banjir $10-25 \mathrm{~cm}$.

b. Periode surut $<1$ minggu.

c. Terjadi ketika terdapat air banjir kiriman dari dataran yang lebih tinggi ke arah laut dan area pesisir, sehingga tidak terduga datangnya.

Kedalaman Sedang

a. Ketinggian banjir $25-50 \mathrm{~cm}$.

b. Periode surut 1-2 minggu.

c. Terjadi ketika air pasang normal dan drainase/sungai meluap, biasanya terjadi di awal bulan.

Kedalaman Tinggi

a. Ketinggian banjir $50-75 \mathrm{~cm}$.

b. Periode surut \pm 2 minggu.

c. Terjadi saat pasang maksimum (naik $2 x$ lipat dari normal) sekitar tanggal 12-17 setiap bulannya karna pengaruh bulan purnama penuh.

d. Masyarakat dianjurkan untuk mengungsi.

Kedalaman Sangat Tinggi

a. Ketinggian banjir $75-100 \mathrm{~cm}$.

b. Periode surut $>2$ minggu.

c. Terjadi saat curah hujan dengan debit air tinggi sehingga terjadi penumpukan air.

d. Masyarakat sudah mengungsi dan meninggalkan rumah.

\section{Simbiosis}

Simbiosis diartikan sebagai hubungan yang saling membutuhkan, sebagai tatanan dunia baru 
harus benar-benar digunakan untuk menggambarkan bentuk hubungan antara dua elemen dasar yang berbeda yang saling eksklusif. (Kurokawa, 1991)

Dalam buku Kisho Kurokawa, men-simbiosiskan beberapa hal yang berbeda bukan berarti menyatukan perbedaan-perbedaan tersebut, namun untuk dapat menghasilkan sesuatu yang baru dengan adanya penggabungan. Simbiosis merupakan sebuah percobaan untuk menemukan elemen-elemen dasar atau aturan-aturan tanpa menghapus oposisi antara elemen-elemen tersebut. Filosofi simbiosis menghancurkan dualisme, dan dalam arsitektur digunakan untuk menggabungkan dua tempat yang berbeda fungsi dan kegiatan yang berbeda menjadi sesuatu yang baru dan memiliki dampak yang baik bagi kedua belah pihak dan dapat mencapai prospek dan fisibilitas yang diharapkan. (Kurokawa, 1991)

\section{Arsitektur Resiliensi}

Kata resiliensi berasal dari Bahasa Inggris yaitu resilience yang memiliki arti yaitu gaya pegas, gaya lenting, atau kegembiraan.

Namun kata Resilience dalam dunia arsitektur sendiri dapat diartikan sebagai kemampuan untuk pulih dari atau menyesuaikan diri dengan mudah terhadap kemalangan atau perubahan.

Arsitektur resiliensi sendiri harus dapat menjadi tempat bernaung yang memberi kenyamanan bagi penggunanya dalam menghadapi bencana maupun kondisi alam maupun lingkungan yang tidak diinginkan dan bersifat merugikan manusia maupun makhluk hidup disekitar lingkungan tersebut.

Dalam arsitektur, resiliensi merupakan suatu kemampuan untuk mempertahankan maupun mengembalikan fungsionalitas ketika menghadapi kejadian-kejadian yang memberi dampak negatif. Resiliensi merupakan bentukan yang lebih baru dan kompleks dari kata keberlanjutan dimana resiliensi menekankan tidak hanya pada kontinuitas, namun juga kemampuan arsitektur tersebut untuk kembali bangkit setelah menghadapi gangguan yang merusak. Resiliensi merupakan gabungan yang komprehensif dari ketahanan dan adaptivitas dalam menghadapi perubahan-perubahan keadaan. (Istiadji, Hardiman, \& Satwiko, 2018)

3 Parameter arsitektur yang resiliensi dalam buku "Resilience and Development - Positive Life Adaptations" (Glantz \& Johnson, 2002), antara lain:

a. Perancangan yang memungkinkan bangunan tersebut belajar dari lingkungan dan menyesuaikan diri berbagai kondisi termasuk bencana alam.

b. Menggunakan penemuan dan ilmu dari proses perancangan sebelumnya atau dari arsitek maestro agar dapat di aplikasikan ke desain selanjutnya.

c. Melibatkan seluruh aspek kehidupan pada kawasan dan lingkungan tempat perancangan agar dapat menjawab persoalan, menghadirkan program yang dibutuhkan dan meningkatkan nila guna bangunan.

\section{Sentra Budidaya dan Pengolahan Bandeng}

Sentra didefinisikan sebagai pusat kegiatan di kawasan tertentu dimana usahanya menggunakan bahan baku, menghasilkan produk yang sama atau sejenis serta memiliki prospek untuk dikembangkan menjadi lebih maju.

Budidaya didefinisikan sebagai suatu proses memperbanyak sumber daya hayati, yang biasanya terdapat dalam bidang perkebunan, peternakan, dan pertanian.Pengolahan didefinisikan sebagai suatu perbuatan, cara, atau proses mengolah sesuatu hal agar mencapai bentuk atau tahapan yang diinginkan atau lebih sempurna.

Proyek Sentra Budidaya dan Pengolahan Bandeng ini merupakan sebuah wadah yang di desain agar dapat menampung seluruh proses industri rumahan yang sudah dilakukan masyarakat Tambakrejo mulai dari pembibitan dan pembesaran bandeng, panen, produksi (pemasakan), 
pengemasan, penjualan hingga distribusi Ikan Bandeng agar dapat menghasilkan produk olahan dengan kualitas dan kuantitas yang lebih tinggi.

\section{METODE}

Metode penelitian yang digunakan adalah penelitian kualitatif dengan memperhatikan beberapa aspek perancangan seperti, yaitu:

\section{a. Metode Simbiosis}

Pengaplikasian metode simbiosis adalah dengan mengkolaborasikan aspek ekonomi Tambakrejo yaitu budidaya dan pengolahan Ikan Bandeng dan aspek hunian untuk shelter sementara saat banjir dengan menggunakan budaya abangan (aspek lokalitas) sebagai perantaranya tanpa menghilangkan entitas dari masing-masing aspek (Gambar 3).

b. Metode Arsitektur Resiliensi

Pengaplikasian metode arsitektur resiliensi membuat proyek ini menjadi adaptif sehingga dapat digunakan secara efektif baik saat kering sebagai pasar dan dapur pengolahan ikan bandeng, maupun saat banjir rob sebagai shelter sementara penduduk Tambakrejo.

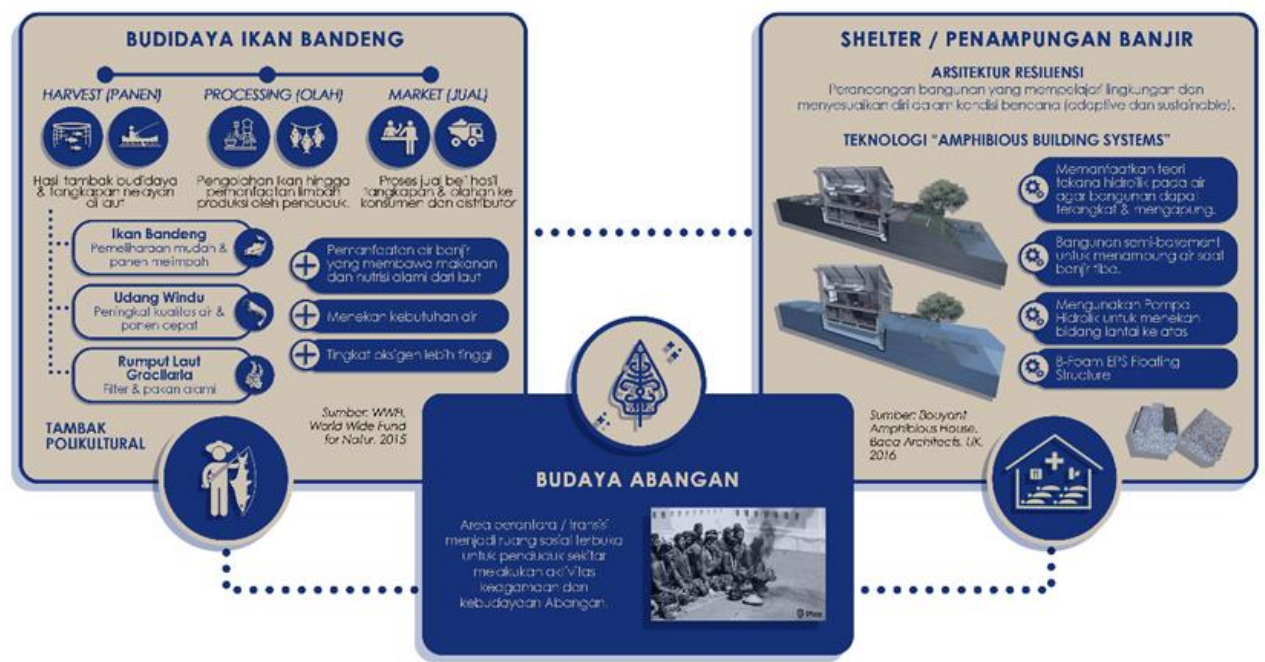

Gambar 3. Penerapan Metode Simbiosis Pada Proyek Sumber: Penulis, 2021

\section{DISKUSI DAN HASIL}

\section{Pengaplikasian Metode Simbiosis}

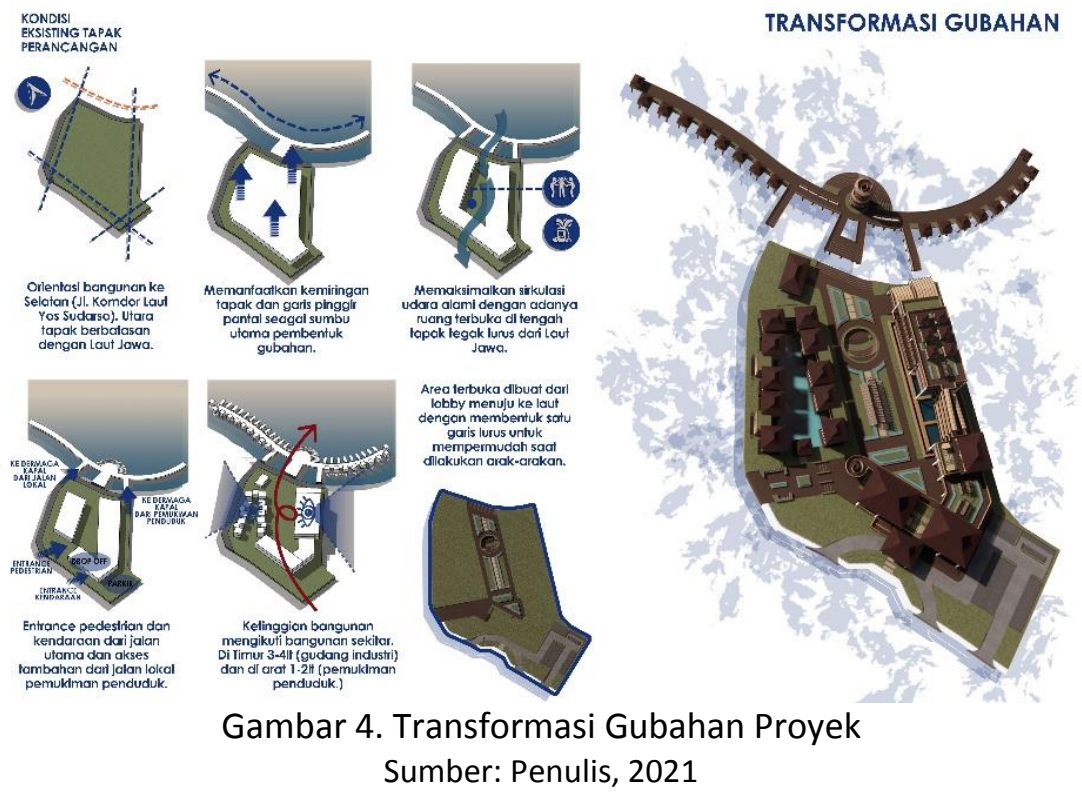


Pengaplikasian simbiosis dapat terlihat dari proses transformasi gubahan terutama di zoning horisontal pada tapak yang ingin mempermudah akses masyarakat dimana zona untuk bangunan apung berdekatan dengan hunian masyarakat pada kiri tapak, zona ekonomi berada pada kanan tapak yang memiliki fasilitas parkir, dan juga zona budaya di tengah tapak yang mengarah laut (Gambar 4).

Terdapat beberapa jalur entrance yang disediakan dan dapat diakses dengan jalan kaki maupun perahu karet saat banjir ke shelter (bangunan apung) untuk masyarakat mengungsi antara lain akses utama dari Jl. Komdor Laut Yos Sudarso untuk kendaraan bermotor dan bus, akses pedestrian dari samping tapak yang berdekatan dengan pemukiman masyarakat dan juga akses untuk para nelayan dari arah area parkir kapal di laut untuk menurunkan hasil tangkapan .

Untuk menjaga privasi dan kenyamanan penghuni saat terjadi banjir maka gubahan yang bersifat publik seperti pasar, dapur pengolahan dan juga tambak terletak bersebarangan dengan gubahan shelter. Kedua gubahan utama ini lalu dihubungkan dengan plaza terbuka yang dapat digunakan oleh warga untuk berkumpul, melakukan upacara adat, aral-arakan maupun syukuran bersama. Dan sebagai penunjang pada bagian laut ditambahkan dermaga sebagai titik akhir dari arak-arakan ke laut, saung pemancingan untuk pengunjung dan juga area parkir kapal untuk menurunkan hasil tangkapan. Disinilah simbiosis berperan yaitu dengan mengkolaborasikan dan menampung kegiatan ekonomi warga, menampung kegiatan kebudayaan agar dapat dijadikan sebagai ikon wisata, dan menampung masyarakat yang membutuhkan tempat pengungsian layak tanpa menghilangkan nilai dan kepentingan masingmasing fungsi tersebut.

\section{Pengaplikasian Metode Arsitektur Resiliensi}
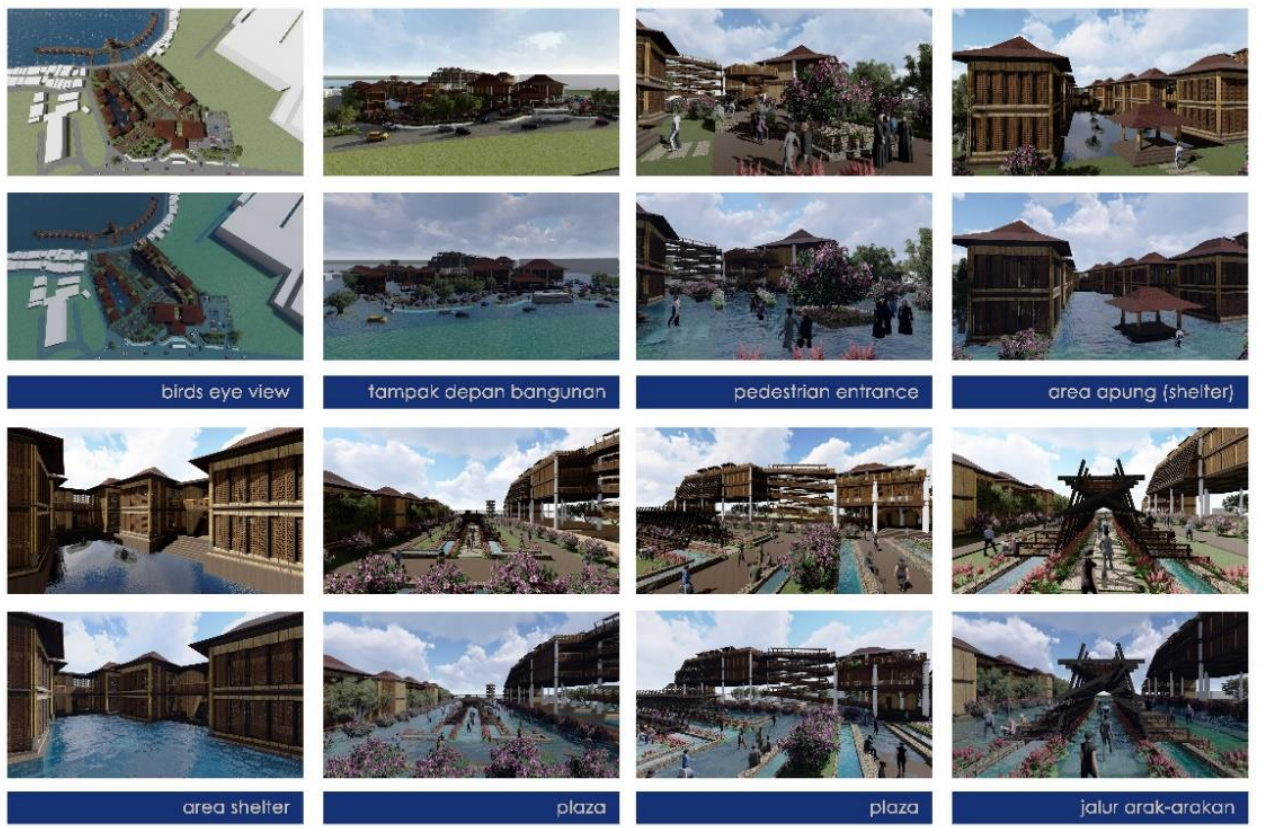

Gambar 6. Kondisi Bangunan Saat Kering dan Banjir Sumber: Penulis, 2021

Salah satu keunggulan bangunan ini yaitu menggunakan metode arsitektur resiliensi sehingga bersifat adaptif dan dapat tetap bergerak serta beraktivitas secara efektif dan produktif baik saat terjadi kering maupun saat banjir rob melanda kawasan ini. Sehingga masyarakat tidak harus khawatir tentang kondisi ekologi sekitar terutama pada intensitas pasang-surut air laut, namun dapat bersimbiosis dan beradaptasi antara manusia, dan ekologi atau alam itu sendiri 
tanpa salah satu pihak merasa dirugikan (Gambar 8). Malah sebaliknya, kehadiran banjir rob ini dapat digunakan sebagai salah satu potensi untuk menarik minat masyarakat untuk datang ke bangunan ini dengan menawarkan atraksi air, upacara adat budaya Abangan dan juga hasil olahan Ikan Bandeng.

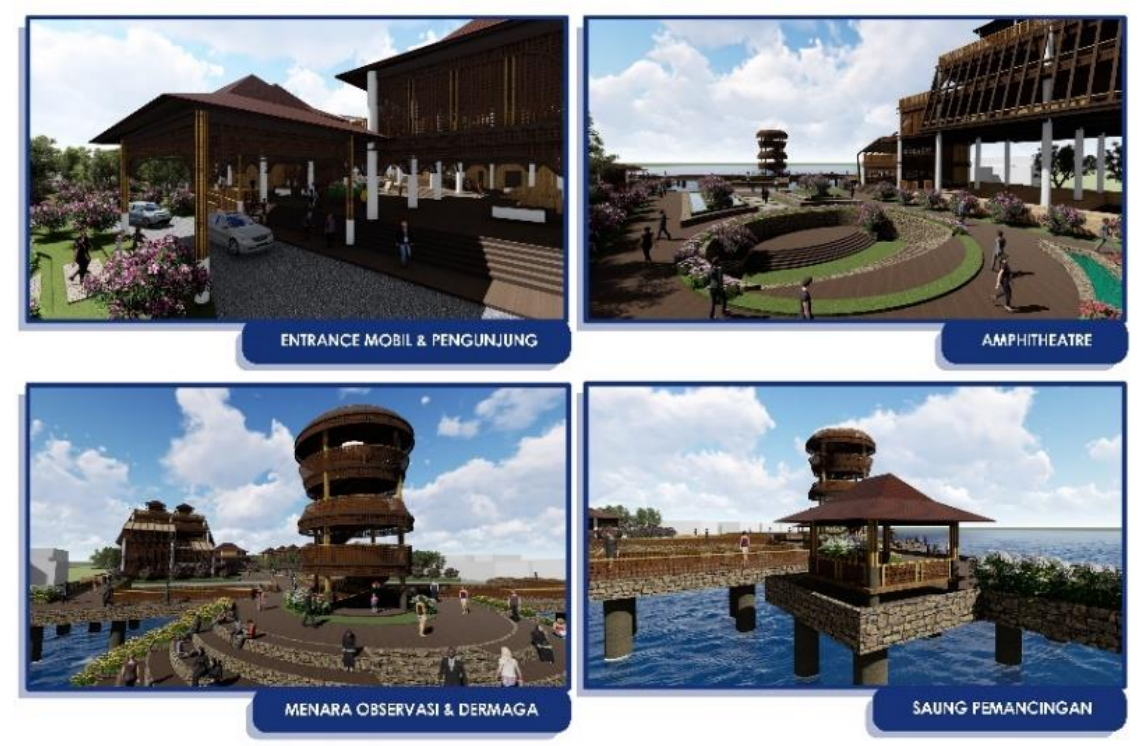

Gambar 6. 3D Eksterior Proyek Tanadah

Sumber: Penulis, 2021

(Gambar 6) Karna bangunan yang bersifat lokal dengan fungsi utama ditunjukkan untuk masyarakat Tambakrejo maka arsitektur bangunan tetap mempertahankan tipologi-tipologi khas Semarang atau Jawa yaitu atap Joglo untuk memberikan kesan dan suasana vernakular. Hal ini juga membantu proyek bangunan ini untuk beradaptasi dengan lingkungan sekitar yang masih memiliki bentuk bangunan vernakular. Bangunan juga sebagian besar dibuat terbuka untuk memaksimalkan view atau pemandangan dari laut dan penghawaan alami pada tapak agar dapat disirkulasikan keseluruh area pada tapak.

\section{KESIMPULAN DAN SARAN}

\section{Kesimpulan}

Banjir rob merupakan salah satu aktivitas ekologi atau alam yang tidak dapat dihindari maupun dikontrol oleh sebab itu kita sebagai manusia hanya bisa berlapangdada dan mendoakan agar banjir rob ini tidak sering terjadi. Sayangnya, di Kelurahan Tambakrejo hampir setiap bulan banjir rob dapat terjadi dan memberikan kerugian serta menganggu laju aktivitas masyarakat dalam kehidupan sehari-hari yang menyebabkan tingkat kemiskinan di kawasan ini meningkat setiap tahunnya.

Rancangan proyek ini mencoba untuk menghadirkan sebuah bangunan adaptif yang dapat beradaptasi dan membantu masyarakat Tambakrejo untuk melalui rutinitas banjir rob bulanan ini dengan menjadi wadah ekonomi yang memanfaatkan kehadiran banjir rob sebagai pengairan budidaya, wadah untuk berproduksi (pengolahan hasil budidaya) dan saat dibutuhkan dapat menjadi wadah penampungan sementara. Bangunan ini disempurnakan dengan aspek lokalitas yang diaplikasikan kedalam bangunan baik dalam fungsi yaitu sebagai wadah adat dan budaya abangan setempat maupun pada fasad dan bentuk bangunan yang menggunakan ciri khas kawasan yaitu atap Joglo dan rumah panggung sehingga bangunan dapat menyesuaikan kawasan dengan mudah.

Oleh sebab itu kehadiran proyek ini diharapkan dapat membantu masyarakat dalam 
menstabilkan perekonomian dengan memberikan lahan pekerjaan yang sesuai dengan potensi kawasan. Serta dapat meningkatkan mutu hidup dan kekreativitasan masyarakat Tambakrejo sekaligus. Selain itu, visi lainnya dari proyek ini adalah memberikan pandangan atau paradigma baru kepada masyarakat bahwa aktivitas alam atau ekologi tidak hanya memberikan hal-hal negatif yang merugikan saja namun juga dapat dimanfaatkan dan disyukuri kehadirannya atau bahkan mungkin nantinya dapat dinantikan kehadirannya tiap bulan oleh penduduk maupun pengunjung.

\section{Saran}

Aktivitas dan gejala alam memang semakin kompleks dan beragam tiap tahun bahkan tiap harinya, begitu juga dengan arsitektur yang selalu mengikuti perubahan dan kebutuhan manusia. Proyek Tanadah ini merupakan suatu proyek yang mencoba untuk kembali untuk mengingatkan kita para arsitek untuk merancang bukan hanya untuk kepentingan kita manusia saja. Namun, kita sebagai arsitek seharusnya yang mencoba untuk mengerti dan menghargai ekologi dengan membuat sebuah desain yang mengikuti dan kembali berporos pada alam sebagai salah satu aspek yang tak boleh terlupakan. Sehingga, suatu desain itu tidak hanya mencoba untuk mengurangi segala aktivitas alam yang mungkin dianggap tidak menguntungkan, namun desain tersebut juga harus adaptif dan mencoba menerima kehadiran aktivitas tersebut dalam bangunan.

\section{REFERENSI}

Badan Penanggulangan Bencana Daerah Kota Semarang. (2020, Januari 1). BPBD Semarang Kota. Dipetik Maret 17, 2020, dari http://bpbd.semarangkota.go.id/pages/databencana

Dinas Komunikasi dan Informatika Kota Semarang. (2019, Januari 1). Data dan Profil Kota Semarang. (Pemerintah Daerah Kabupaten Semarang) Dipetik Maret 15, 2021, dari https://main.semarangkab.go.id/profile/kondisi-umum/geografi-dan-topografi/

Erlani, R., \& Nugrahandika, W. (2019). Ketangguhan Kota Semarang dalam Menghadapi Bencana Banjir Pasang Air Laut (Rob). Jurnal Perencanaan Pembangunan Daerah dan Pedesaan, 3(1), 47-63. doi:http://dx.doi.org/10.29244/jp2wd.2019.3.1.47-63

Glantz, M., \& Johnson, J. (2002). Resilience and Development - Positive Life Adaptations. Boston: Springer Science \& Business Media.

Istiadji, A., Hardiman, G., \& Satwiko, P. (2018). Studi Kerangka Konseptual Resilience Dalam Konstelasi Konsep Gerakan Lingkungan. Jurnal Arsitektur Universitas Diponegoro, 7(48), 439-452. Diambil kembali dari http://digilib.mercubuana.ac.id/manager/t!@file_artikel_abstrak/Isi_Artikel_4140143 79609.pdf

Kurokawa, K. (1991). Intercultural Architecture - The Philosophy of Simbiosis. Tokyo: Markus Zhand.

Moerti, W. (2020). Data BNPB Sepanjang 2020: Banjir, Bencana Alam Paling Banyak Terjadi. Jakarta: Merdeka.com. Dipetik Maret 15, 2021, dari https://www.merdeka.com/peristiwa/data-bnpb-sepanjang-2020-banjir-bencanaalam-paling-banyak-terjadi.html

Nuswantoro. (2020). Ketika Rob Rendam Pesisir Utara Jawa Tengah. Semarang: Mongabay Situs Berita Lingkungan. Dipetik April 10, 2021, dari 
https://www.mongabay.co.id/2020/06/07/ketika-rob-rendam-pesisir-utara-jawatengah/

Taufiqurrahman, E. (2017, Juni 13). Seluk Beluk Pasang Surut Air Laut. (Langitselatan.com) Dipetik April 10, 2021, dari Langit Selatan:

https://langitselatan.com/2017/06/13/seluk-beluk-pasang-surut-air-laut/

Wibowo, A. (2021). Ribuan Rumah Di Kelurahan Tambakrejo Terendam Banjir. Semarang: Kantor Berita RMOL JATENG. Dipetik April 14, 2021, dari https://www.rmoljateng.com/read/2021/02/25/34738/Ribuan-Rumah-Di-KelurahanTambakrejo-Terendam-Banjir-

Wikipedia Indonesia. (2021, Maret 22). Wikipedia. (Wikipedia) Dipetik Maret 28, 2021, dari https://id.wikipedia.org/wiki/Ekologi 